\title{
Design and Simulation on Automatic Door System of Factory Workshop
}

\author{
Xie Fuxiang \\ School of Mechanical-electronic and Vehicle Engineering \\ Weifang University \\ Weifang, P.R.China \\ e-mail: xfx608@126.com
}

\begin{abstract}
In order to study the automatic door systems of factory workshop, and attain low cost and high reliability requirements, the automatic door systems was designed in the factory workshop, door size was determined, material selected and accessories on door was designed. The system was consisted of the main controller, sensor probes, power systems, go round and spreader system, gearing device and guide system under the door. Take the actual center distance $a_{\text {s }}$ is $2638 \mathrm{~mm}$, and body weight of the single door was $56.6 \mathrm{~kg}$, and the total weight was $113.2 \mathrm{~kg}$.Virtual test analysis by ADAMS software show that change in displacement of three coordinate directions on the automatic doors in factory workshop was produced, and mainly affected by the motion force of the three directions. The force in the Y-direction was maximum. Power consumption was maximum during the middle motion time.
\end{abstract}

Keywords-Factory workshop;Automatic door; system; design; simulation

\section{INTRODUCTION}

Save energy on air conditioning, reduce noise, prevent dust and wind by automatic doors, while allowing entrance looked very solemn grade and widely used in foreign countries. In China, independent research and development of automatic doors was not yet mature. The current design of the automatic door is mainly used for High Speed Train ${ }^{[1-4]}$, Bus ${ }^{[5]}$, Animal building ${ }^{[6]}$ as well as Rolling doors ${ }^{[7-}$ ${ }^{8]}$.The relevant literature was not more used of automatic doors in the factory workshop. Therefore, according to the factory workshop requirements, automatic door system in factory workshop was designed, which has automatic sensor switch, adjustable speed, low cost and high reliability.

\section{DESIGN OF AUTOMATIC DOOR}

\section{A. Structure and working principle}

Automatic door structure was showed in Fig .1, The system was consisted of the main controller, sensor probes, power systems, go round and spreader system, gearing device and guide system under the door. The main controller is the command center of the automatic doors, through an internal instruction program on massive and compiled blocks, sent the appropriate command, and directed motor or electric locks system to work, while adjusting the speed of the host controller to open the doors, and turning on the magnitude of other parameters. Sensing probe was responsible for collecting external signal, when there was moving objects into its operating range, and the main controller a pulse signal was given. Power system was provided the active force to open and close, acceleration and deceleration control doors. Go round and spreader system was went round the doors on hanging activity, while the doors was driven under power traction. Motor power was transmitted by Gearing device, and moving Go Round and Spreader System. guide system under the door was the lower part of the leaf orientation and positioning device, to prevent doors before and after the door swing at runtime.

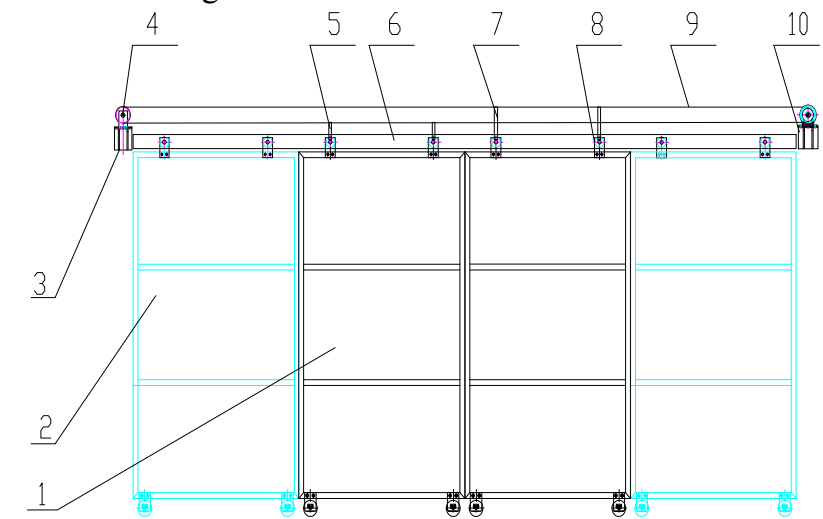

1 Doors closed 2 Doors open 3 Limit switches 4 Drive sprocket 5 Left leaf spreader 6 Transmission7 Right leaf spreader 8 Spreader and go round system 9 Chain 10 Power Systems

Figure 1.Structure on automatic door of factory workshop

\section{B. Transmission mechanism design}

Mechanical design of automatic doors included mounting plate, the road track, three-phase AC motor, drive chain, sprockets, deceleration devices, track wheels, hanger and so on. Objects was designed in accordance with wall hole of the factory workshop, there were width is $3 \mathrm{~m}$ and height is $3 \mathrm{~m}$, combined with consideration of the applicable environment, which is mainly used of cargo transportation and pedestrian fewer occasions in workshops.

This section requires the rotation of the motor was transformed linear reciprocating motion, and after comparing the advantages and disadvantages of chain drive, worm gear, gear drive and chain drive, and automatic door environment, the system eventually used a chain drive, which advantages can transmit motion and 
power in the case of two-axis center distant, able to work at low speed, heavy-duty and high temperature dust flying conditions and adverse environments. Compared with other transmission mode, it can ensure accurate average transmission ratio, transmission power is large and acting on the shaft and the bearing force is small, higher transmission efficiency and usually ranging is 0.95 to 0.97 [9-11].

1) Selected the sprocket teeth

Chain Drive Ratio is $i=\frac{n_{1}}{n_{2}}=\frac{1000}{310}=3.23$

Selected from Table small sprocket teeth $Z_{1}$ is 25 , and Large sprocket teeth $\mathrm{Z}_{2}$ is $i Z_{1}=3.23 \times 25=81$ 。

2) Computing power

Known chain drive to work smoothly, motor drive, through look-up table selection $K_{A}$ is 1.3 , To calculate the power:

$$
P_{C}=K_{A} P=1.3 \times 0.75 \mathrm{KW}=0.975 \mathrm{KW}
$$

3 ) Tentatived center distance $a_{0}$, take a number of chain links $\mathrm{Lp}$ to tentative center distance, recommended $\mathrm{a}_{0}$ is $(30 \sim 50) \mathrm{p}$, took $\mathrm{a}_{0}$ is $46 \mathrm{p}$.

$$
\begin{aligned}
& \mathrm{L}_{\mathrm{p}}=\frac{2 \mathrm{a}_{0}}{\mathrm{p}}+\frac{\mathrm{z}_{1}+\mathrm{z}_{2}}{2}+\left(\frac{\mathrm{z}_{2}-\mathrm{z}_{1}}{2 \pi}\right) \frac{\mathrm{p}}{\mathrm{a}_{0}} \\
& =\frac{2 \times 46 \mathrm{p}}{\mathrm{p}}+\frac{25+81}{2}+\frac{81-25^{2}}{2 \pi} \frac{\mathrm{p}}{46 \mathrm{p}}=134.72 \\
& \mathrm{P}_{0}=\frac{P c}{K z K l K p}=\frac{0.975}{1.34 \times 1.08 \times 1}=0.674 \mathrm{KW}
\end{aligned}
$$

$$
a_{0}=\frac{p}{4}\left[\left(L_{p}-\frac{z_{1}+z_{2}}{2}\right)+\sqrt{\left(L_{p}-\frac{z_{1}+z_{2}}{2}\right)^{2}-8\left(\frac{z_{2}-z_{1}}{2 \pi}\right)^{2}}\right]
$$

So $\mathrm{a}_{0}$ is $2643.05 \mathrm{~mm}$

Link number was evenly selected is 136 .

4) determined the chain pitch

First the coefficients were determined $K_{Z}, K_{L}, K_{P}$.

Small sprocket teeth coefficient were looked up by Mechanical Design Handbook, $K_{Z}$ is 1.34 , $K_{L}$ is $1.08, K_{P}$ is 1 , choose Single-row chain.

According to A series of single-row roller chains rated power curve selection of roller chain model was $10 \mathrm{~A}$, chain pitch was found by Mechanical Design Handbook is $15.875 \mathrm{~mm}$

5) determined the chain length and center distance Chain length $L$ is:

$$
L=L_{P} \times p / 1000=136 \times 15.875 / 1000=3.5 \mathrm{~m}
$$

Decreased the amount of Center distance:

$\Delta a=(0.002 \sim 0.004) a$

$=(0.002 \sim 0.004) 2643.3=5.29 \sim 10.57 \mathrm{~mm}$

The actual center distance:

$$
\begin{aligned}
& a_{s}=a-\Delta a \\
& =2643.3-(5.29 \sim 10.57)=2638.01 \sim 2632.73 \mathrm{~mm}
\end{aligned}
$$

Take the actual center distance $a_{s}$ was $2638 \mathrm{~mm}$.

\section{Driven System Design}

Design requirements of automatic doors should be as small as possible noise, the closing process must not have collision phenomenon, frequently opened and closed can be achieved, open and closed the door should be in place, and the volume can not be too big, so AC motor was chosen.

Body weight of the single door was $56.6 \mathrm{~kg}$, and the total weight was $113.2 \mathrm{~kg}$. Gravity was $\mathrm{F}=113.2 \times 9.8=1109.36 \mathrm{~N} \cdot \mathrm{m}$. Because friction on the rolling movement of the door leaf, through checking that the rolling friction coefficient of the steel and the steel was 0.15 to 0.2 , So sliding door from the desired tension was F1:

$$
\mathrm{F} 1=1109.36 \times 0.15 \sim 1109.36 \times 0.2=166.4 \mathrm{~N} \sim 221.9 \mathrm{~N}
$$

Selection of gear transmission ratio is 9, motor power is $0.75 \mathrm{kw}$, rated torque is $5.0 \mathrm{~N} \cdot \mathrm{m}$, rated speed is $1000 \mathrm{r} / \mathrm{min}$, sprocket radius is $75 \mathrm{~mm}$, drawn tension reducer is

$$
\mathrm{F} 2=5 \times 9 \div 0.075=600 \mathrm{~N}
$$

According to F2> F1, the doors can be pull.

\section{Doors traveling rail system}

The lower portion of the automatic door was leaf guide and positioning devices, there can be prevented the door leaf swing phenomenon in operation, to ensure that the door travels in a predetermined direction. The advantage of this structure is that it can ensure the reliability of the door movement, reducing the door wear, low noise and energy saving.

\section{E. crane system}

Crane system was used of hanging doors activities, to boost the doors while running through the power traction, and motor rotation is converted to movement of the door. In order to make the system capable of moving, the door leaf is designed in a straight line on the shift rail, and to ensure the transmission reliability of the system.

\section{F. decelerated device}

Between the prime mover and worker or executing device, Decelerator was played role in matching the speed and delivering torque, which was a relatively sophisticated machinery, and aimed to reduce the speed.

\section{G. body, limit switches}

Two doors were equipped with two hangers by hanging round, and moving on the track. The chain on the upper of hanging wheel was fixed and connected with the lower of the door. Sensors are divided into contact and non-contact sensors. Due to their different works and led to its installation location was different. This design used two limit switches ${ }^{[12]}$. 


\section{VIRTUAL TEST}

\section{A. Test Methods}

Virtual prototyping was completed by virtual test software ADAMS, open and close automatic doors of the factory workshop were researched, followed by analysis of the state of motion automatic doors and power variation in the switching state.

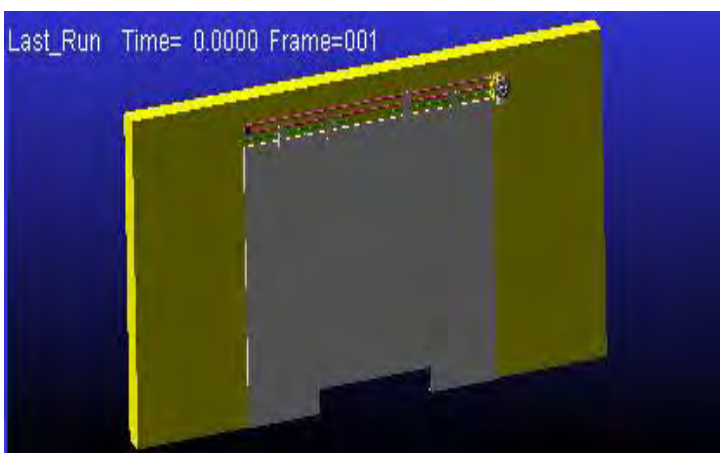

\section{B. Experimental results and analysis}

Fig .2 was virtual results on workshop of the automatic door opening and closing. Virtual tests showed that automatic doors in the switching process can be stabilized in accordance with constant speed. In the switching process, moving speed and transmission device was controlled by a power drive system, to finish automatic door motion the process of the factory floor.

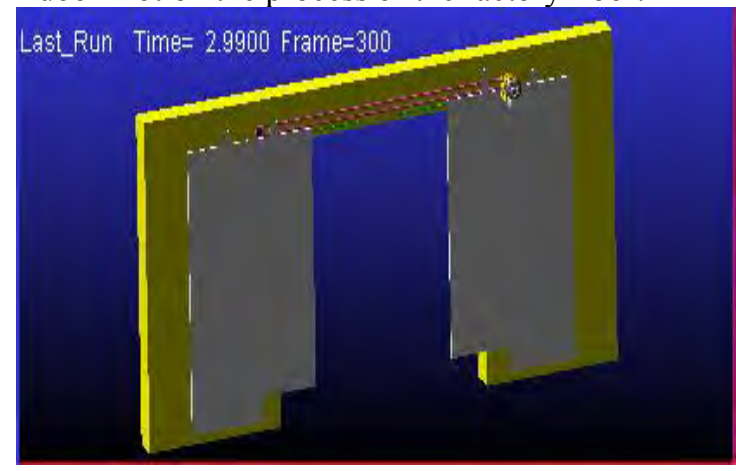

Figure 2.Virtual results on workshop of the automatic door opening and closing

Simulation results on automatic door of factory workshop was shown in Fig .3. Fig .3 (a, b, c, d) was respectively the motion and power consumption of the automatic door as a change in the curve. In the test, the automatic door in the $\mathrm{X}$ direction (i.e., perpendicular to the leaf direction), resulting in a relatively small displacement, as shown in Fig .3a. Described the force of the automatic door along the vertical direction to the movement door. The displacement in the $\mathrm{Z}$ direction (i.e., the leaf vertical direction) was changed, the change at this time was larger than the displacement amount of change in the displacement direction $X$, as shown in Fig .3b. Displacement in the $\mathrm{Y}$ direction (leaf movement direction)

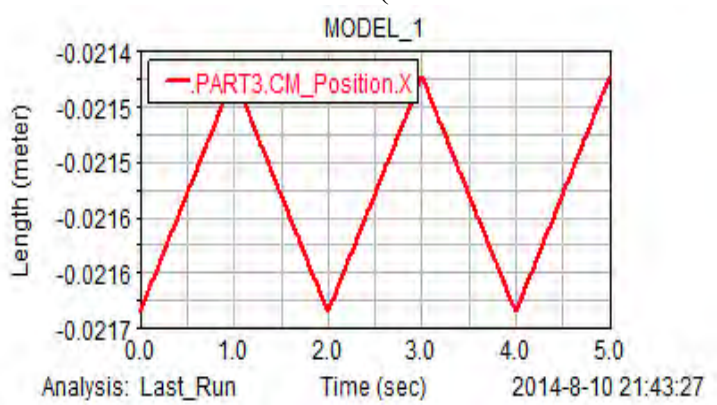

(a)

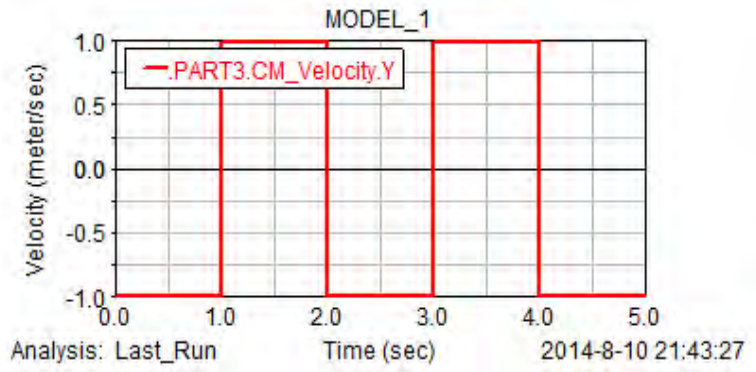

(c) has more regularity, the change of displacement amount is consistent with the open and close doors. Moving speed of automatic door opened and closed was uniform and smooth operation, as shown in Fig .3c. In the middle period of the power consumption was the largest, as shown in Fig.d.

Virtual Tests showed that displaced on the automatic door of factory workshop was changed in 3 coordinate direction. The force are produced in the process of movement by three main directions, the force in the $\mathrm{Y}$ direction was maximum. In the middle period of Power consumption during exercise was maximum.

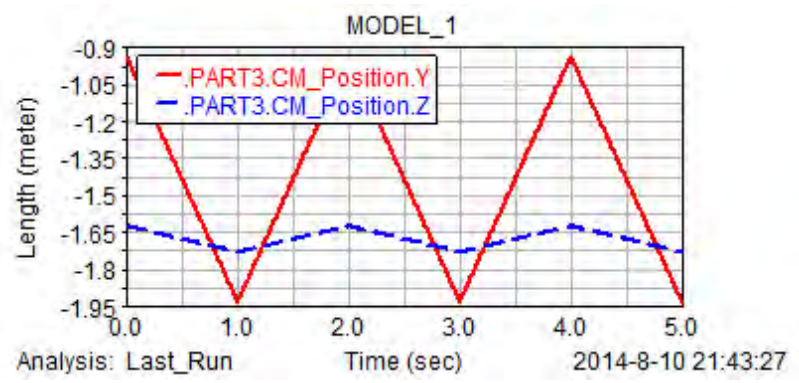

(b)

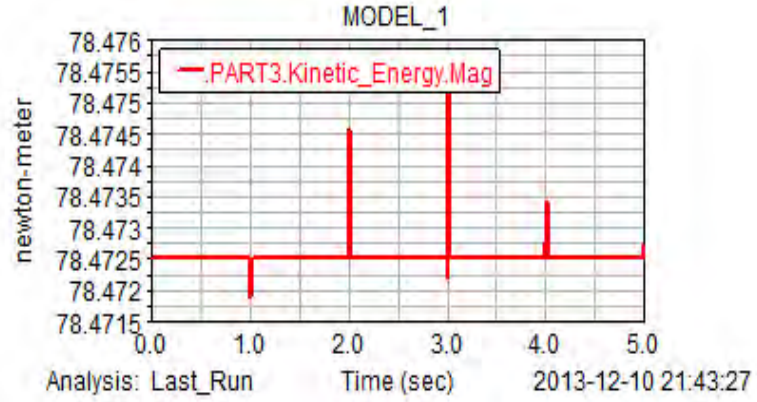

(d)

Figure 3.Motion simulation test results on automatic door of factory workshop 


\section{CONCLUSION}

The entire automatic door system of factory workshop was designed, door size was determined, material selected and accessories on door was designed.

In order to achieve low cost, high reliability, etc., the automatic door system of factory workshop was designed, and mainly consisted of the main controller, sensor probes, power systems, go round and spreader system, gearing device and guide system under the door.

Virtual Tests showed that displaced on the automatic door of factory workshop was changed in 3 coordinate direction. The force are produced in the process of movement by three main directions, the force in the $\mathrm{Y}$ direction was maximum. In the middle period of Power consumption during exercise was maximum.

\section{ACKNOWLEDGMENT}

The author wishes to express his sincere thanks to colleagues from the School of Mechanical-electronic and Vehicle Engineering Weifang University, and sponsor from the Science and Technology Development Project of Weifang(201301046) and The project on Doctoral Scientific Research Foundation funded of Weifang University (2013BS07) .

\section{REFERENCES}

[1] Shao Xu. Study of Optimal Control for Automatic Door Control System Used in Electric Multiple Units[D].jilin university.2010.5.

[2] LIU Changying, CUIQiming, GAO Yinhan. Study on Control System for Electric Automatic Door in High Speed Train. Machine Tool\&Hydraulics.2010.8(38):19 23.

[3] Ren Baokuan,Zeng Tao.Research on the driver's eye movement characteristics.Journal of NanYang Institute of Technology. 2012.6(4):63 65.

[4] ZAI Wen-jiao. Design and realization of automatic door based on AT89c51 MCU[J]. Journal of Southwest University for Nationalities Natural Science Edition.2013.4(39):655 658.

[5] Xia Tian,Wang Jing.Simulation Research of Automobile Motordriven Door System[J].Equipment Manufactring Technology.2009.1:27 28.

[6] Qi Yuqiang,Zhao An.Design and configuration control for the automatic door of an animal house[J].Journal of Changchun university of Techonology.2009.6(30):665 668

[7] Zhang Feiyun.Design of Step Motor Controller for Rolling Door and Ventilator of Vegetable Greenhouse[J].Hubei Agricultural Sciences. 2013.15 (52):3681 3684.

[8] Zhang Fujun,Huang Shuang,Liu Kun.Design of Step Motor Serial Controller for Rice Seedlings Tent Book Door[J]. Journal of Agricultural Mechanization Research。2012.8:65 68.

[9] [9] Mechanical design manual editorial board. Mechanical design manual(Fifth Edition) [M]. Mechanical Industry Press, 2004,9

[10] Li Hongxun. Automatic door Engineering - the design, processing and installation[M]. China water conservancy and Hydropower Press, 2009,3

[11] $\mathrm{Pu}$ Lianggui. Mechanical design(Eighth Edition) [M]. Higher education press, 2010,5

[12] Feng Qingxiu. Mechanical and electrical transmission control" (Fifth Edition) [M]. Huazhong University of Science and Technology press, 2011,6 